\title{
METODOLOGIA PARA AVALIAÇÃO DO DESEMPENHO DE RECEPTOR DE GPS DE USO AGRÍCOLA EM CONDIÇÃO CINEMÁTICA
}

\author{
THIAGO M. MACHADO ${ }^{1}$, JOSÉ P. MOLIN ${ }^{2}$, FABRÍCIO P. POVH ${ }^{3}$, JOSÉ V. SALVI ${ }^{4}$
}

RESUMO: São inúmeras as aplicações das tecnologias de Global Navigation Satellite System (GNSS), e o sistema mais utilizado é o Global Positioning System (GPS), desenvolvido pelos Estados Unidos. Em aplicações agrícolas, há a necessidade de posicionamento estático e cinemático, com demandas de distintos níveis de acurácia. No entanto, os usuários carecem de informação quanto ao desempenho cinemático de receptores GNSS, sendo disponibilizados apenas dados de desempenho estático, e por essa razão desenvolveu-se um veículo instrumentado para testar metodologia de avaliação do desempenho de receptores GNSS sob condição cinemática, visando a representar operações agrícolas. Foi utilizada instrumentação para coletar os dados sob variação de velocidade e sentido de percurso circular. A partir de ensaio experimental, verificou-se que a metodologia possibilita o cálculo da acurácia e da precisão, necessitando apenas de melhorias nos equipamentos de aquisição de dados em ensaios de longa duração.

PALAVRAS-CHAVE: agricultura de precisão, GPS, ensaio cinemático.

\section{METHODOLOGY FOR ASSESSING THE GPS RECEIVER PERFORMANCE OF AGRICULTURAL USE UNDER KINEMATIC CONDITION}

\begin{abstract}
Activities that use Global Navigation Satellite System (GNSS) are countless and the most used one is the Global Positioning System (GPS) developed by the United States. In precision agriculture there are demands for static and cinematic positioning with distinct levels of accuracy for different applications; nevertheless cinematic performance data are not available as manufacturers of GPS receivers present only static performance information. For this reason it was developed an instrumented vehicle to test a methodology of performance evaluation of GPS receivers in kinematic conditions, which is representative to agricultural operations. A set of instrumentation was composed and used for collecting data under variable speed and rotation direction. Tests were conducted showing that the methodology allows to measure accuracy and precision, but improvements have to be implemented on the instrumentation equipment for long term tests.
\end{abstract}

KEYWORDS: precision agriculture, GPS, kinematic tests.

\section{INTRODUÇÃO}

O GNSS, sigla para o termo Global Navigation Satellite System (sistema de navegação global por sátelite), engloba o Global Positioning System (GPS) dos Estados Unidos, o Global'naya Navigatsionnay Sputnikovaya Sistema (GLONASS) da Rússia, o GALILEO da União Europeia e o Beidou ou Compass da China (MONICO, 2007). Pela popularidade e pela disponibilidade, o sistema que merece destaque é o GPS, e são inúmeras as atividades viabilizadas ou auxiliadas pelo mesmo. Segundo STOMBAUGH et al. (2002) e WELTZIEN et al. (2003), os fabricantes de receptores de GPS utilizados em agricultura de precisão, usualmente, apenas disponibilizam

\footnotetext{
${ }^{1}$ Eng ${ }^{\circ}$ Agrícola, Doutorando, FCA/UNESP, Departamento de Engenharia Rural, Botucatu - SP, Fone: (0XX14) 8111.7445 thiagomartinsmach@yahoo.com.br

${ }^{2}$ Eng $^{\mathbf{0}}$ Agrícola, Livre Docente, Departamento de Engenharia de Biossistemas, ESALQ/USP, Piracicaba - SP, Fone: (0XX19) 3447.8502,jpmolin@esalq.usp.br

${ }^{3}$ Eng ${ }^{0}$ Agrônomo, Doutorando, Departamento de Produção Vegetal, ESALQ/USP, Piracicaba - SP.

${ }^{4}$ Eng $^{\mathrm{o}}$ Agrônomo, Doutorando, Departamento de Produção Vegetal, ESALQ/USP, Piracicaba - SP.

Recebido pelo Conselho Editorial em: 22-8-2008

Aprovado pelo Conselho Editorial em: 12-12-2009
}

Eng. Agríc., Jaboticabal, v.30, n.1, p.121-129, jan./fev. 2010 
relatórios do desempenho de seus receptores no modo estático, que nem sempre são indicativos de desempenho cinemático.

Uma das razões da falta de informação dos fabricantes sobre a acurácia cinemática dos receptores GNSS é a ausência de padrão estabelecido para ensaios cinemáticos. STOMBAUGH et al. (2002) e WELTZIEN et al. (2003) propuseram padronizações para ensaios cinemáticos de receptores GNSS, fixando as antenas dos receptores em um braço que rodava à velocidade constante, sendo as coordenadas do círculo abrangido determinadas por um receptor GPS RTK (Real Time Kinematic). As vantagens de utilizar um aparato desses é que o mesmo permite maior repetitividade dos ensaios do que com um veículo em percursos de campo, por exemplo. Diversos autores (HAN et al., 2002; EHSANI et al., 2003) têm avaliado o desempenho de receptores de GNSS com as antenas montadas sobre veículos deslocando-se a diferentes velocidades, usualmente utilizando um receptor de GPS RTK como referência para os cálculos da acurácia e da precisão.

Nessas condições, MOLIN \& CARRERA (2006) testaram quatro receptores, com três velocidades de deslocamento, e observaram que, em velocidades menores, o erro é maior quando o receptor é configurado para coletar um dado de posição por segundo $(1 \mathrm{~Hz})$. Já CHOSA et al. (2007) desenvolveram uma plataforma circular de ensaio cinemático para receptores de GPS RTK, mensurando a variação de velocidade e o erro do ângulo de trajetória, tendo como referência um detector magnético de pulsos.

É fundamental que essas informações relacionadas ao desempenho cinemático dos diferentes tipos de receptores, bem como das tecnologias associadas se tornem disponíveis para os usuários que demandam posicionamento estático e cinemático, e as poucas informações relativas ao desempenho dos receptores de mercado dizem respeito a ensaios estáticos. Sendo assim, o presente trabalho teve o objetivo de desenvolver e testar metodologia para o ensaio cinemático a fim de avaliar o desempenho de receptores de GNSS, buscando simular aplicações agrícolas cinemáticas, como mapeamento de colheitas, aplicação de insumos em taxa variável e navegações em campo.

\section{MATERIAL E MÉTODOS}

Para a realização do ensaio com receptor GPS, foi escolhido um veículo que tivesse a possibilidade de variar a velocidade e manter-se estável em uma mesma trajetória, trafegando sobre um gramado. Nessa fase, adotou-se como veículo, um minitrator equipado com motor ciclo Otto, de 2,57 kW de potência, movido a gasolina, com rotação máxima de $3.500 \mathrm{rpm}$ e equipado com transmissão mecânica de seis marchas.

Em um terreno plano, foi instalado um pivô com a função de ancorar o veículo por meio de um cabo de aço (Figura 1a) e instalou-se uma trava para fixar a direção do veículo de forma a tracionar continuamente o cabo de aço, permitindo que o mesmo executasse percursos circulares em trajetória constante. Sobre o veículo, construiu-se uma plataforma para comportar a instrumentação necessária para a coleta de dados (Figura 1b).

Foi utilizado um detector óptico de pulsos (encoder), modelo incremental, série 58, marca Hohner, com rotação máxima de trabalho de 6.000 rpm e 240 pulsos por giro, para medir a distância percorrida e a velocidade de deslocamento do veículo. Como roda odométrica, foi utilizada uma estrutura pantográfica com uma roda de bicicleta, para o acionamento do detector óptico de pulsos, resultando em resolução de $5 \mathrm{~mm}$ para mensuração de deslocamento. 


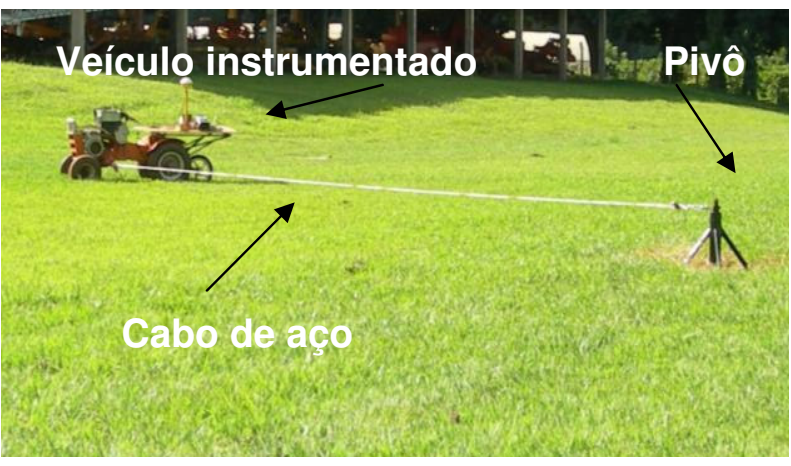

(a)

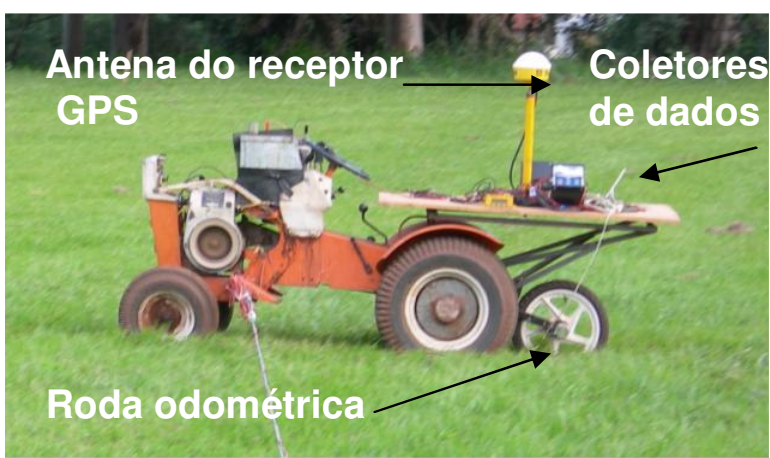

(b)

FIGURA 1. Pivô de fixação, cabo de aço e veículo instrumentado realizando movimentos circulares em seu entorno (a); instrumentação montada sobre a plataforma, roda odométrica, antena do receptor de GPS e coletores de dados (b). Anchoring pivot, cable and instrumented vehicle performing circular movements around itself (a) instrumentation over the platform, cycling wheel, GPS antenna, datalogger (b).

Para marcar o início e o final das voltas, foi utilizado um sensor fotoelétrico modelo BA2MDDT-P PNP, marca Autonics, com tempo de resposta de $1 \mathrm{~ms}$. Para a coleta de dados, foi adaptado um coletor (Coletor de Dados Agrícola - CDA), marca ENALTA, responsável por armazenar os dados gerados pelo receptor de GPS (velocidade, latitude, longitude, altitude, tempo, número de satélites, satélites ativos, PDOP e disponibilidade de correção diferencial). Esse coletor possibilita obter informações sobre o sinal do detector óptico de pulsos, contando o número de pulsos a cada atualização da sentença do GPS, na sequência do arquivo National Marine Electronics Association (NMEA), nos formatos GGA, VTG e GSA. É composto por um hardware de 4 MB de memória, sensores e programa com comunicação via USB.

Os testes do sistema e da metodologia foram conduzidos utilizando-se de receptor de GPS, modelo AG 132, marca Trimble, com 12 canais e frequência de atualização de $1 \mathrm{~Hz}$. Em função de inconsistências relacionadas a travamentos, observadas no sistema de coleta de dados, ainda em desenvolvimento, adotou-se tempo de coleta de 15 minutos por repetição ou tratamento.

O ensaio foi realizado em gramado localizado no Departamento de Engenharia Rural, da ESALQ/USP, com coordenadas $22^{\circ} 42^{\prime} 48^{\prime \prime} \mathrm{S}$ e $47^{\circ} 37^{\prime} 42^{\prime \prime} \mathrm{W}$. Para o cálculo do erro de trajeto, foi estabelecido um marco de referência no centro do percurso (pivô), com um receptor L1/L2 geodésico, modelo Hiper GGD, marca Topcon, coletando dados pelo método de posicionamento estático, com máscara de elevação de $15^{\circ}$, durante $1 \mathrm{~h} 30$, com intervalo amostral de $15 \mathrm{~s}$, e pósprocessados para a determinação das coordenadas.

A coordenada de referência foi utilizada no cálculo dos erros, sendo transportada para o perímetro do percurso circular a partir de uma planilha especialmente desenvolvida no programa Microsoft Excel ${ }^{\circledR}$. Os dados obtidos do receptor de GPS, em coordenadas geográficas, são transformados para UTM e transferidos para a planilha eletrônica juntamente com os pulsos contados em cada coordenada, os dados do perímetro da roda que aciona o detector óptico, os pulsos por volta da roda e o raio do percurso. A partir desses dados, determinaram-se o Erro de Trajeto (ET) e suas componentes norte e leste [eqs. (1) a (9) e Figura 2].

A distância (D) percorrida pela roda odométrica entre dois registros de coordenadas é:

$$
\mathrm{D}=\frac{\operatorname{Pr} \mathrm{Np}}{240}
$$

em que,

Pr - perímetro da roda, $\mathrm{m}$, e

$\mathrm{Np}$ - número de pulsos do detector óptico. 
O ângulo $(\alpha)$ descrito para percorrer a distância $\mathrm{D}$ é:

$$
\alpha=\frac{\mathrm{D}}{\mathrm{R}}
$$

em que,

$\alpha$ - ângulo, rad, e

$\mathrm{R}$ - raio da circunferência descrita pela roda odométrica, $\mathrm{m}$.

A posição da roda odométrica nos sentidos norte e leste é dada por:

$$
\begin{aligned}
& \mathrm{PN}=\operatorname{sen}(\alpha) \mathrm{R} \\
& \mathrm{PE}=\cos (\alpha) \mathrm{R}
\end{aligned}
$$

em que,

$\mathrm{PN}$ - posição norte, $\mathrm{m}, \mathrm{e}$

$\mathrm{PE}$ - posição leste, $\mathrm{m}$.

As posições em UTM foram obtidas a partir das posições norte e leste adicionadas da coordenada UTM adotada como referência, que está no centro da circunferência (pivô), ou seja:

$$
\begin{aligned}
& \mathrm{PRN}=\mathrm{PN}+\mathrm{CRN} \\
& \mathrm{PRE}=\mathrm{PE}+\mathrm{CRE}
\end{aligned}
$$

em que,

PRN - posição de referência norte, m;

PRE - posição de referência leste, $m$;

$\mathrm{CRN}$ - coordenada de referência norte, $\mathrm{m}$, e

CRE - coordenada de referência leste, $\mathrm{m}$.

Assim, obtêm-se os desvios entre a circunferência de referência (do veículo) e a circunferência obtida pelo receptor de GPS, que são os erros nas direções norte e leste, ou seja:

$$
\begin{aligned}
& \mathrm{EN}=\mathrm{PRN}-\mathrm{CGPSN} \\
& \mathrm{EE}=\mathrm{PRE}-\mathrm{CGPSE}
\end{aligned}
$$

em que,

EN - erro na direção norte, m;

EE - erro na direção leste, $\mathrm{m}$;

CGPSN - coordenada do GPS ensaiado norte, e

CGPSE - coordenada do GPS ensaiado leste.

Assim, obtém-se o ET (m):

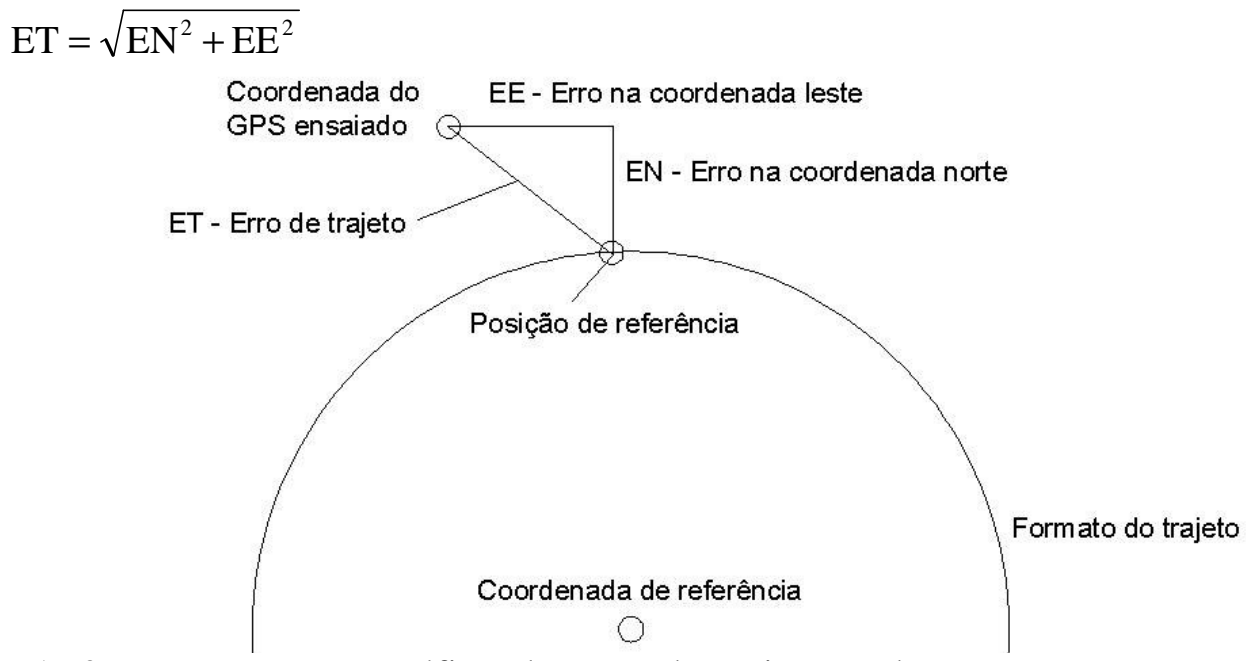

FIGURA 2. Representação gráfica do erro de trajeto e de suas componentes leste e norte. Graphical representation of trajectory error and its East and North components. 
Outros indicadores de acurácia (incluindo tendência e precisão) foram utilizados (BUICK, 2002; EHSANI et al., 2003; WELTZIEN et al. , 2003; STOMBAUGH et al., 2005) e descritos nas eqs.(10) a (13).

O desvio-padrão $(1 \sigma)$ indica que $68,27 \%$ de todos os erros (EN, EE) ocorreram dentro dos limites de $\pm 1 \sigma$, representando a precisão, pois usa a diferença de erro de posição e a média do erro de posição e resulta na indicação da dispersão das coordenadas obtidas ao longo do período de coleta.

$$
\sigma_{N j}=\sqrt{\frac{1}{n-1} \sum_{i=1}^{n}(E N i j-\overline{E N j})^{2}} \sigma_{E j}={\sqrt{\frac{1}{n-1} \sum_{i=1}^{n}(E E i j-\overline{E E j})^{2}}}^{2}
$$

em que,

$\sigma_{\mathrm{Nj}}$ - desvio-padrão dos erros da coordenada $\mathrm{N}$;

$\sigma_{\mathrm{Ej}}$ - desvio-padrão dos erros da coordenada E;

ENij e EEij - diferença entre coordenada de referência e coordenada do receptor ensaiado (erro);

$\overline{\mathrm{EN}} \mathrm{je} \overline{\mathrm{EEj}}$ - média dos erros das coordenadas do receptor ensaiado, que representa a tendência, e

n - número total de coordenadas coletadas "ij" de um tratamento "j".

$$
\sigma=\sqrt{\sigma_{\mathrm{E}}^{2}+\sigma_{\mathrm{N}}^{2}}
$$

A raiz quadrada da média do erro ao quadrado (root mean square) - RMS, indica a acurácia, pois não utiliza a média, resultando no erro absoluto em relação à referência, com $68,27 \%$ de probabilidade, ou seja:

$$
\mathrm{RMS}=\sqrt{\frac{\sum_{\mathrm{i}=1}^{\mathrm{n}} \mathrm{ET}^{2}}{\mathrm{n}}}
$$

O erro circular provável (CEP) indica um limite com probabilidade de $50 \%$ dos pontos coletados em um determinado período se encontrarem na região (área) definida pelo CEP (VIEIRA, 2007).

$$
\mathrm{CEP}=1,18 \sqrt{\sigma_{\mathrm{E}}^{2}+\sigma_{\mathrm{N}}^{2}}
$$

O período orbital dos satélites GPS é de aproximadamente 12 horas siderais, portanto a posição dos satélites se repete a cada dia, 4 minutos antes que a do dia anterior (MONICO, 2007). Considerando que os experimentos foram repetidos sob as mesmas condições de geometria dos satélites, atmosféricas, e mantendo as alturas dos receptores, é de se esperar que os efeitos sistemáticos apresentem o mesmo comportamento.

A partir dessas considerações e visando a testar o conjunto da instrumentação, o procedimento de transformação dos dados e o método de cálculo dos erros, foi realizada uma série de percursos arranjados dia a dia, adiantando seu início em 4 minutos em relação ao dia anterior, de forma que fosse permitido que esses ocorressem em dias consecutivos, embora, neste caso, não tenha sido realizado um ensaio com repetições.

Adotaram-se as velocidades médias de deslocamento de $0,34 \mathrm{~m} \mathrm{~s}^{-1}, 1,22 \mathrm{~m} \mathrm{~s}^{-1}$ e 1,60 $\mathrm{m} \mathrm{s}^{-1}$, disponíveis no veículo instrumentado, bem como sentido de percurso horário e anti-horário como variáveis independentes, além da configuração de ativação do filtro interno do receptor de GPS submetido ao ensaio, fixada para intensidade normal de filtragem, segundo orientação do fabricante.

O princípio destes filtros é usar conceitos estatísticos para comparar uma medida atual com uma medida que foi previamente estimada e, com essa comparação, evitar o espalhamento dos pontos. A maior aplicação desses filtros tem sido exatamente na utilização desses receptores em aplicações agrícolas, como geradores de sinal para orientação em passadas paralelas com sistemas 
tipo "barra de luz". Nesse caso, oferecem maior precisão no paralelismo em curto espaço de tempo, o que não se confunde com repetibilidade de posicionamento ao longo do tempo, caracterizando a acurácia. Há receptores com a opção de configuração de várias intensidades de filtragem, e aumentando a intensidade, aumenta-se a precisão (BUICK, 2002).

Antes de iniciar os percursos, os coletores de dados e o receptor de GPS eram ligados, e assim permaneciam por 5 minutos. Em seguida, dava-se partida no veículo, que realizava três voltas e, na sequência, iniciava-se a coleta de dados por um tempo de 25 minutos. Dos 25 minutos de coleta de dados, eliminavam-se os 5 minutos iniciais e os 5 minutos finais, utilizando dados dos 15 minutos centrais.

\section{RESULTADOS E DISCUSSÃO}

Como não se encontraram coletores de dados com as características necessárias, disponíveis comercialmente, esse teve de ser desenvolvido e adaptado para atender às necessidades demandadas. Em função da grande quantidade de dados e visando a não correr riscos de perdas, utilizaram-se dois coletores para executar funções distintas. Assim, um ficou dedicado a contar os pulsos do detector óptico, e o outro, para a gravação dos dados.

Os equipamentos eletrônicos utilizados (coletor de dados, sensor fotoelétrico, detector óptico de pulsos) não apresentaram problemas ou limitações de comunicação, possibilitando contar, sincronizar e armazenar dados em espaços de tempo menores que $1 \mathrm{~s}$. Apesar de ter apresentado problemas de inconsistência, o coletor cumpriu o objetivo, que era de sincronizar os dados coletados do receptor de GPS com os pulsos adquiridos do detector de pulsos magnéticos. No entanto, observa-se que há necessidade de aprimoramento no coletor, com o aumento da capacidade de memória, resistência do hardware e do programa que coleta e armazena os dados. Além disso, na obtenção dos valores de erros para as coordenadas, não se consideraram possíveis deformações, como dilatação e expansão do cabo de aço, e a variação da pressão de ar no pneu da roda de acionamento do detector óptico.

$\mathrm{Na}$ Figura 3, estão apresentados exemplos de resultados gráficos do ensaio realizado, mostrando o percurso de referência (círculo vermelho) e pontos obtidos com o receptor ensaiado (círculo preto) em condição cinemática. Dentre outros, observa-se deslocamento dos erros para a direção oeste - leste (Figura 3a) e na direção norte - sul (Figura 3b).

$\mathrm{Na}$ Tabela 1, apresentam-se os resultados de desempenho do receptor de GPS ensaiado, realizando percursos, variando a velocidade de deslocamento, ativação e desativação do filtro do receptor, e variação do sentido de rotação do veículo.

O ET e o RMS, indicativos de acurácia em relação à referência, não mostraram tendência de estarem influenciados pela velocidade de deslocamento. Com a elevação da velocidade, nota-se aumento dos valores de $\sigma$ e CEP, que são indicativos de precisão, sendo essa diferença maior quando o receptor está com o filtro desativado (percursos 7 ao 12).

STOMBAUGH et al. (2002), em ensaio cinemático de receptores GPS em plataforma de percurso circular, com velocidade constante de $3,14 \mathrm{~m} \mathrm{~s}^{-1}$, testaram a ativação e a desativação de filtros de receptores; encontraram acurácias menores em receptor com filtro ativado. Os autores descrevem que, para testes mais detalhados, para avaliar o desempenho dos filtros dos receptores de GPS, deve-se testar o receptor simulando percursos curvos e retos. Com esses tipos de percursos, tem-se variação brusca de sentido, podendo ser mais eficientes para testes de filtros que usam algoritmos internos, ficando mais semelhante ao ambiente agrícola onde o receptor é utilizado.

STOMBAUGH et al. (2005) construíram uma plataforma de ensaio simulando operações agrícolas com retas e curvas e separaram os erros por partes do percurso. Nos ensaios, encontraram RMS variando de $1,60 \mathrm{~m}$ a $5,80 \mathrm{~m}$ em trajeto simulando operações agrícolas, com receptores semelhantes a este aqui ensaiado. Também verificaram que, em curvas fechadas, um dos receptores, com filtro interno ativado, apresentou atraso para responder às mudanças bruscas de trajetória, ocasionando elevação dos níveis de erros. 


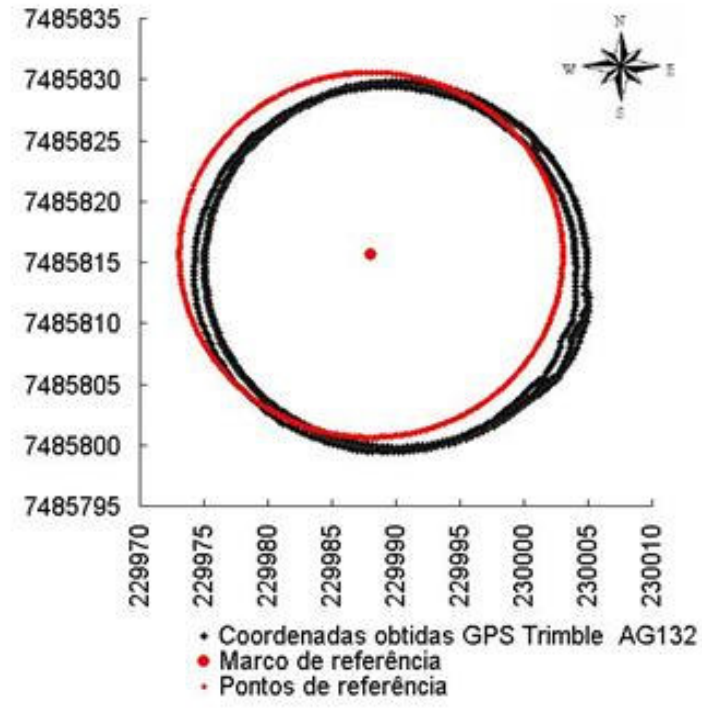

(a)

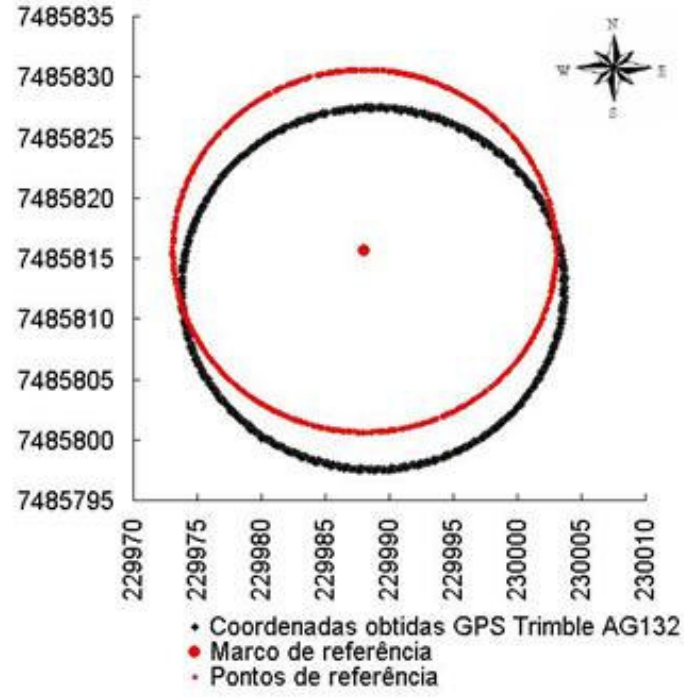

(b)

FIGURA 3. Percursos demarcados pelo receptor de GPS com o veículo sob velocidade de deslocamento de $0,39 \mathrm{~m} \mathrm{~s}^{-1}$, com o receptor GPS configurado com o filtro ativado em intensidade normal (a); velocidade de deslocamento do veículo de $1,07 \mathrm{~m} \mathrm{~s}^{-1}$, com o filtro desativado (b). Tracks demarked by the GPS receiver with the vehicle under forward speed of $0.39 \mathrm{~m} \mathrm{~s}^{-1}$, with the GPS receiver set up with filter activated at normal intensity (a); vehicle forward speed of $1.07 \mathrm{~m} \mathrm{~s}^{-1}$, with inactivated filter.

TABELA 1. Resultado dos indicadores de desempenho do receptor de GPS ensaiado, utilizando recursos de configuração de filtro interno, diferentes velocidades de deslocamento do veículo e sentido de rotação. Results of performance indicators for the tested GPS receiver, using internal filter configuration, vehicle forward speeds and rotation direction.

\begin{tabular}{cccccccccccccc}
\hline$* \mathrm{P}$ & SR & Filtro & $\begin{array}{c}\text { Vel } \\
\left(\mathrm{m} \mathrm{s}^{-1}\right)\end{array}$ & PD & $\begin{array}{c}\text { ET } \\
(\mathrm{m})\end{array}$ & $\begin{array}{c}\text { RMS } \\
(\mathrm{m})\end{array}$ & $\begin{array}{c}\sigma \\
(\mathrm{m})\end{array}$ & $\begin{array}{c}\text { CEP } \\
(\mathrm{m})\end{array}$ & $\begin{array}{c}\text { Emín. } \\
(\mathrm{m})\end{array}$ & $\begin{array}{c}\text { Emáx. } \\
(\mathrm{m})\end{array}$ & $\begin{array}{c}\text { EL } \\
(\mathrm{m})\end{array}$ & $\begin{array}{c}\text { EN } \\
(\mathrm{m})\end{array}$ & $\begin{array}{c}\text { EV } \\
(\%)\end{array}$ \\
\hline 1 & $\mathrm{H}$ & Sim & 0,38 & 2,13 & 0,62 & 0,65 & 0,22 & 0,26 & 0,02 & 1,63 & 0,59 & 0,16 & $-0,92$ \\
2 & $\mathrm{H}$ & Sim & 1,26 & 4,54 & 0,59 & 0,64 & 0,34 & 0,41 & 0,04 & 1,10 & 0,53 & 0,55 & $-0,62$ \\
3 & $\mathrm{H}$ & Sim & 1,18 & 2,35 & 0,89 & 0,92 & 0,37 & 0,44 & 0,46 & 1,51 & 0,57 & 0,62 & 0,04 \\
4 & $\mathrm{H}$ & Sim & 1,63 & 2,26 & 0,62 & 0,70 & 0,39 & 0,46 & 0,02 & 1,35 & 0,29 & 0,50 & $-0,35$ \\
5 & $\mathrm{H}$ & Sim & 1,57 & 2,30 & 1,11 & 1,15 & 0,43 & 0,51 & 0,43 & 1,86 & 0,47 & 0,95 & $-0,24$ \\
6 & H & Sim & 0,30 & 1,90 & 1,08 & 1,08 & 0,09 & 0,11 & 0,88 & 1,26 & 0,26 & 1,04 & $-1,19$ \\
7 & H & Não & 0,40 & 2,26 & 1,06 & 1,07 & 0,20 & 0,24 & 0,74 & 1,49 & 0,80 & 0,69 & $-0,83$ \\
8 & H & Não & 1,14 & 2,50 & 1,25 & 1,26 & 0,34 & 0,40 & 0,78 & 1,69 & 1,18 & 0,29 & $-0,85$ \\
9 & H & Não & 1,07 & 1,86 & 3,16 & 3,16 & 0,26 & 0,31 & 2,67 & 3,73 & 0,64 & 3,09 & $-0,42$ \\
10 & H & Não & 1,40 & 2,13 & 0,85 & 0,89 & 0,37 & 0,44 & 0,25 & 1,30 & 0,75 & 0,30 & $-0,66$ \\
11 & H & Não & 1,55 & 1,92 & 1,84 & 1,87 & 0,45 & 0,53 & 1,26 & 3,41 & 1,71 & 0,62 & $-1,02$ \\
12 & H & Não & 0,40 & 2,05 & 0,98 & 1,00 & 0,33 & 0,39 & 0,47 & 4,69 & 0,87 & 0,37 & $-0,10$ \\
13 & H & Sim & 0,39 & 1,83 & 1,96 & 1,99 & 0,48 & 0,57 & 1,07 & 2,88 & 1,68 & 0,95 & $-1,09$ \\
14 & A & Sim & 0,37 & 1,82 & 1,27 & 1,29 & 0,25 & 0,30 & 0,79 & 1,67 & 0,22 & 1,25 & $-0,70$ \\
15 & H & Sim & 1,09 & 2,12 & 1,31 & 1,33 & 0,35 & 0,41 & 0,78 & 1,88 & 1,24 & 0,34 & $-0,84$ \\
16 & A & Sim & 1,24 & 2,20 & 0,72 & 0,79 & 0,43 & 0,50 & 0,01 & 1,24 & 0,56 & 0,35 & $-0,63$ \\
17 & H & Sim & 1,46 & 2,39 & 1,79 & 1,82 & 0,46 & 0,55 & 1,14 & 2,40 & 1,51 & 0,89 & $-0,11$ \\
18 & A & Sim & 1,63 & 2,53 & 0,73 & 0,77 & 0,41 & 0,48 & 0,06 & 1,45 & 0,64 & 0,68 & $-1,10$ \\
\hline
\end{tabular}

*P - percurso; SR - sentido de rotação (H - horário, A - anti-horário); Vel - velocidade de deslocamento; PD - PDOP; ET - Erro de trajeto; RMS - raiz quadrada média do erro; $\sigma$ - desvio-padrão; CEP - erro circular provável; Emín. - erro mínimo; Emáx.- erro máximo; EL - erro na coordenada leste; EN - erro na coordenada norte; EV - erro de velocidade. 
A precisão não apresentou nenhuma tendência quanto ao sentido de percurso, mas os indicadores de acurácia RMS e ET foram maiores no sentido horário dos percursos 13 ao 18 . Os erros de direção mostraram-se variáveis, não apresentando tendências. EHSANI et al. (2003), testando o erro de trajeto com receptor L1/CA, trafegando em duas direções, leste-oeste e norte-sul, encontraram erros de trajeto maiores nas coordenadas norte-sul, quando o ensaio era realizado no sentido de caminhamento leste-oeste.

A partir dos dados, foi ainda possível quantificar os erros de velocidade de deslocamento obtidos a partir do receptor de GPS e compará-los com aqueles obtidos a partir do detector óptico de pulsos, considerado como referência. Nesse caso, não se consideraram possíveis derrapagens da roda de acionamento do detector óptico de pulsos (roda odométrica). Os erros de velocidade mostraram-se alternados, não seguindo tendências, exceto no percurso 3, onde a velocidade resultou maior que a da referência. MOLIN et al. (2005) obtiveram erros de velocidade em um receptor GPS $41 \%$ inferiores sob condição de aceleração e $18 \%$ superiores em condição de desaceleração, não encontrando diferença em condição de velocidade constante, comparado com um detector óptico de pulsos.

O procedimento de coleta e de análise dos dados demonstrou que é importante que se possa montar uma infraestrutura que permita experimentos com diferentes receptores ao mesmo tempo, bastando para isso que o sistema de coleta de dados seja aprimorado. Também deve ser possível a coleta de dados por períodos mais longos. Esses e outros recursos podem permitir uma padronização de ensaios com comparabilidade e que serviria aos usuários para a correta seleção de receptores de GNSS para as diferentes demandas usuais da agricultura moderna.

\section{CONCLUSÕES}

A metodologia de obtenção de dados de coordenadas em condição cinemática, com o receptor de GPS montado sobre um veículo com instrumentação apropriada, permitiu o cálculo de erros de trajeto e a caracterização do desempenho desse receptor. No entanto, são necessárias melhorias, principalmente na robustez do coletor de dados, que permitam a realização de ensaios com coletas de dados em períodos mais longos, e vários receptores ao mesmo tempo, para permitir comparações entre receptores, configurações e sinais de correção.

\section{AGRADECIMENTOS}

Projeto apoiado pela Fundação de Amparo à Pesquisa do Estado de São Paulo - FAPESP.

\section{REFERÊNCIAS}

BUICK, R. GPS guidance-making an informed decision. In: INTERNATIONAL CONFERENCE OF PRECISION AGRICULTURE, 3., 2002, Minneapolis. Proceedings ... Madison: ASA/CSSA/SSSA, 2002. p.1.979-2.004.

CHOSA, T.; OMINE, M.; ITANI, K. Dynamic performance of global positioning system velocity sensor for extremely accurate positioning. Biosystems Engineering, London, v.97, n.1, p.3-9, 2007.

EHSANI, M. R.; SULLIVAN, M. D.; ZIMMERMAN, T. L.; STOMBAUGH, T. Evaluating the Dynamic Accuracy of Low-Cost GPS Receivers. St. Joseph: ASABE, 2003. 13 p. (Paper No.031014).

HAN, S.; NOH, H.K.; ZHANG, Q.; SHIN, B.S. Dynamic performance evaluation of DGPS receivers for parallel tracking. St. Joseph: ASABE, 2002. 15 p. (Paper No. 023107).

MOLIN, J.P.; CARREIRA, P.T. Metodologia para ensaios cinemáticos de receptores de GNSS utilizando um GPS RTK como referência. Revista Brasileira de Agroinformática, Viçosa - MG, v.8, n.1, p.53-62, 2006. 
MOLIN, J.P.; SOUZA, A.B.M.; FONTANA, G.; NAGUMO, G.K. Análise comparativa de sensores de velocidade de deslocamento em função da superfície. Engenharia Agrícola, Jaboticabal, v.25, n.3, p.768-773, 2005.

MONICO, J.F.G. Posicionamento pelo GNSS: descrição, fundamentos e aplicações. 2.ed. São Paulo: UNESP, 2007. 476 p.

STOMBAUGH, T.; COLE, J.; SHEARER, S.; KOOSTRA, B. A test facility for evaluating dynamic GPS accuracy. In: EUROPEAN CONFERENCE ON PRECISION AGRICULTURE, 6. 2005, Upsalla. Proceedings... Wageningen: Academic Publishers, 2005. p.605-612.

STOMBAUGH, T.; SHEARER, S.; FULTON, J. Standards for comparison of GPS receiver performance. In: INTERNATIONAL CONFERENCE OF PRECISION AGRICULTURE, 3., 2002, Minneapolis. Proceedings... Madison: ASA/CSSA/SSSA, 2002. p.1.049-1.059.

VIEIRA, W.J. Amostragem por importância em cálculos da probabilidade de acerto em alvos com Monte Carlo. In: SIMPÓSIO DE GUERRA ELETRÔNICA, 2007, São José dos Campos.

Disponível em: <http://www.sige.ita.br/IX_SIGE/Artigos/AA_04.pdf > Acesso em: 21 out. 2009.

WELTZIEN, C.; NOACK, P.; PERSSON, K. GPS receiver accuracy test - dynamic and static for best comparison of results. In: EUROPEAN CONFERENCE ON PRECISION AGRICULTURE, 4., 2003, Berlin. Proceedings... Wageningen: Academic Publishers, 2003. p.717-722. 